\title{
Development of the entomopathogenic hyphomycete Lecanicillium muscarium (Hyphomycetes: Moniliales) on various hosts
}

\author{
HASSAN ASKARY and HAMID YARMAND
}

Plant Protection Department, Research Institute of Forests and Rangelands, P.O. Box: 13185-116, Tehran, Iran; e-mail: askary@rifr-ac.ir

\begin{abstract}
Key words. Sphaerotheca fuliginea, Macrosiphum euphorbiae, Aphidius nigripes, Lecanicillium muscarium, host colonization, scanning electron microscopy
\end{abstract}

\begin{abstract}
The present scanning electron microscopy study describes the development of Lecanicillium muscarium, strain DAOM 198499, on the surface of diverse hosts, including Sphaerotheca fuliginea, a fungal host, and Macrosiphum euphorbiae and Aphidius nigripes, insect hosts. The hosts were sprayed with a conidial suspension of $L$. muscarium $\left(10^{7} \mathrm{conidia} / \mathrm{ml}\right)$. The specimens used in the SEM investigation were collected at particular periods after spraying and prepared for scanning using standard methods. Germination tubes developed twenty-four hours after applying $L$. muscarium conidia to each host. Hyphae were attached to the host by a thin mucilaginous matrix. Seventy-two hours after spraying, hyphae of $S$. fuliginea had collapsed and were encircled by the parasite, and primary sporulation of $L$. muscarium was observed. On the aphid host, colonization started with adherence of the conidia to the host cuticle, followed by conidial germination and growth of mycelium on the surface of the insect's integument. After 48 to $72 \mathrm{~h}$, post colonization, the first sporulation was observed on the cuticle, particularly at articulations. The mode of parasitism of $A$. nigripes by this fungus was similar to that of the aphid. Development of L. muscarium was observed on both mummified aphids (containing the pupae of parasitoids) and adult parasitoids.
\end{abstract}

\section{INTRODUCTION}

For many years considerable attention has been focused on fungi that infect their hosts primarily through their cuticle, because of their potential for reducing populations of sucking insects (Burge, 1988). Despite much effort, the factors determining host specificity and virulence of entomopathogenic fungi are poorly understood and, therefore, complementary data characterizing their mode of action is critically required (Clarkson \& Charnley, 1996). Host specificity may be associated with the physiological state of the host or properties of its integument. Infection via the surface of the host is by active penetration and is one of the most important means by which pathogenic fungi infect their hosts. The invasion of a host is determined by a few aspects of fungal structure and behavior (Charnley, 1989). For example, orientation of germ tubes and attachment to the epicuticle determine the relative virulence of entomopathogenic fungi (St. Leger, 1993; Clarkson \& Charnley, 1996). Highly pathogenic strains of Beauveria bassiana (Bals.-Criv.) Vuill. germinate very quickly and can orientate on the cuticle (Charnley \& St. Leger, 1991). However, the infection processes varies in different fungi. Penetration, colonization and sporulation occurs faster in Metarhizium anisopliae (Metsch.) than in B. bassiana, resulting in the earlier death of hosts infected with the former fungus (Moino et al., 2002).

The entomogenous fungus, Lecanicillium muscarium (Petch) Zare \& Gams, is widely recognized as a promising biological control agent of insect pests and plant parasitic fungi (Askary et al., 1997, 1998, 1999). This hyphomycete is known to have a wide host range. Strains have been collected from nematodes (Meyer et al., 1990), Arachnida, Insecta (see Hall, 1981 and references therein), rusts (Spencer \& Atkey, 1981; Allen, 1982) and other plant-phytopathogenic fungi (Raghavendra-Rao \& Pavgi, 1977; Hall, 1980; Askary et al., 1997, Benhamou \& Brodeur, 2000, 2001). Most isolates, formerly identified as $V$. lecanii, belong to $L$. muscarium, according to Zare \& Gams (2001). The strain DAOM 198499, originally isolated from codling moths, Cydia (Carpocapsa) pomonella L., in Canada, was also reidentified by Zare \& Gams (2001) as this species. It infects, develops and propagates equally well in both arthropods and fungi (Askary et al., 1998). The potato aphid, Macrosiphum euphorbiae Thomas, cucumber powdery mildew, Sphaerotheca fuliginea (Schlechtend: Fr.) Pollacci and the hymenopterous aphid parasitoid, Aphidius nigripes Ashmead are all susceptible to infection by this strain (Askary et al., 1998; Askary \& Brodeur 1999).

Extensive light and transmission electron microscopy studies have been conducted on the pathogenicity and cellular interactions of L. muscarium. But, the exact mechanisms and morphological structures involved in the parasitic process are not well understood (Sitch \& Jackson, 1997). To gain a better insight into the behaviour of the fungus when infecting its hosts, a scanning- electronmicroscopic study was undertaken using strain DAOM 198499.

\section{MATERIAL AND METHODS}

\section{L. muscarium culture}

The L. muscarium strain DAOM 198499, originated from codling moths, C. pomonella, in Canada, was grown in liquid 
aerobic cultures on a nutrient medium, YMPD, in a rotary shaker $\left(1500 \mathrm{rpm}\right.$ and $\left.24^{\circ} \mathrm{C}\right)$. Conidial suspensions of the fungus were obtained from 4-day-old cultures by filtering the culture medium through cheese cloth to remove mycelium. Conidial density was calculated as $1 \times 10^{7}$ conidia per ml using a standard hemocytometer.

\section{Powdery mildew culture, application of pathogen and sam- pling}

Cucumber leaves (Cucumis sativus L.), infected with S. fuliginea (see method in Askary et al., 1998), were cut into leaf disks $(40 \times 40 \mathrm{~mm})$. Four foliage disks (four replicates of each treatment) were each placed on a moist filter paper in a sterile Petri dish. These cucumber leaf disks were sprayed with the conidial suspension of $L$. muscarium. Controls consisted of infected leaf disks sprayed with distilled water. All Petri dishes were closed and incubated at $22 \pm 1{ }^{\circ} \mathrm{C}, 98 \pm 2 \%$ R.H. and a $16 \mathrm{~L}: 8 \mathrm{D}$ photoperiod. Samples $\left(10 \mathrm{~mm}^{2}\right)$ from both control and L. muscariumtreated cucumber leaf disks were collected 24, 48, 72 and $96 \mathrm{~h}$ after spraying, prepared and then subjected as a SEM study.

Potato aphid rearing, application of pathogen and sampling

Potato aphids, obtained using the method of Askary et al., (1998) were transferred to aphid-free potato plants, Solanum tuberosum L., and removed after $24 \mathrm{~h}$. Neonate nymphs were reared and after 5 days 15 third instar aphids were placed on a potato plant. Both, potato plant and aphids were sprayed with 5 $\mathrm{ml}$ of a given concentration of conidia $\left(10^{7}\right.$ conidia $/ \mathrm{ml}$ containing $0.04 \%$ Triton X-100). There were three replicates. Controls consisted of aphids sprayed with distilled water containing $0.04 \%$ Triton X-100. After spraying, aphids were reared in controlled conditions at $21 \pm 0.5^{\circ} \mathrm{C}, 98 \pm 2 \%$ R.H. and a photoperiod of $16 \mathrm{~L}: 8 \mathrm{D}$. Samples from each replicate of both control and treated aphids were collected 24, 48, 72, 96 and $120 \mathrm{~h}$ after spraying, prepared and then subjected as a SEM study.

\section{Parasitoid rearing, application of pathogen and sampling}

Laboratory cultures of A. nigripes (Hymenoptera: Aphidiidae) were established on potato aphids (Brodeur \& McNeil, 1994; Askary \& Brodeur, 1999) using the same methods for rearing the aphid as above.

Fifteen adult parasitoids and early mummified aphids (pupae of the parasitoid) were collected from colonies and placed in Petri dishes and sprayed with $5 \mathrm{ml}$ of conidial suspension $\left(10^{7}\right.$ conidia/ml containing $0.04 \%$ Triton X-100). There were 3 replicates. Controls consisted of parasitoids treated with distilled water containing $0.04 \%$ Triton X-100. Following the treatment, parasitoids were transferred to cups, kept in controlled condition and sampled in the same way as the aphids.

\section{Scanning electron microscopy}

Samples of infected powdery mildew, aphids and parasitoids were vapour-fixed with $1 \%$ osmium tetroxide $(\mathrm{w} / \mathrm{v})$ in 0.1 M-phosphate buffer at $\mathrm{pH} 7.2$ in a sealed Petri dish for $24 \mathrm{~h}$ at room temperature. They were mounted on aluminum stubs, sputter-coated with nickel and observed using a scanning electron microscope $\left(\mathrm{JEOL}^{\circledR}\right)$ operating at $10 \mathrm{kV}$. To study the fungal structures on the hosts, different magnifications were applied as indicated on the photographs.

\section{RESULTS}

\section{Behaviour of $L$. muscarium on powdery mildew}

SEM examination of the powdery mildew, S. fuliginea, (control) showed a normal mycelium and oidium development. Twenty four hours after application of L. muscarium, the antagonist was easily distinguished from the pathogen by its narrower hyphae (Fig. 1A). At this time, the two fungi frequently were observed in close proximity with the hyphae of the antagonist encircling the powdery mildew's cells. Germ tubes of the parasite excreted a mucilaginous matrix on to the powdery mildew mycelium and conidia (Fig. 1B), and in some cases an appressorial shape was observed at the tip of a germ tube (Fig. 1C, arrow). $48 \mathrm{~h}$ after treatment, pathogen damage was more pronounced and mycelial deformation clearly apparent (Fig. 1B, C). The site of penetration became more distinct over time (Fig. 1D). L. muscarium sporulated abundantly on S. fuliginea, 96 and $120 \mathrm{~h}$ after treatment (Fig. 1E).

\section{Behaviour of $\boldsymbol{L}$. muscarium on aphids and parasitoids}

Twenty four hours after inoculation, conidia of L. muscarium were observed adhering to all parts of the bodies of the aphids and parasitoids and the fungus rapidly colonized the surface of the host's cuticle. Germ tubes were produced from single conidia and extended over the cuticle (Figs 2A, B and 3C). A localized fibroid secretion was apparent where the germ tubes and hyphae contacted the host surface (Fig. 2B, arrow). This secretory material was not observed in cultures of L. muscarium on potato dextrose agar. $48 \mathrm{~h}$ after inoculation, germ tubes and mycelium covered the entire surface of aphid and parasitoid bodies, especially articulations (Figs 2F and 3C). Although it was difficult to obtain clear evidence of this process using SEM, some possible sites of penetration of the host cuticle were observed (Figs 2E, 3D). Germ tubes and hyphae were observed all over the aphid and parasitoid bodies. The epicuticle was penetrated without formation of an appressorium-like structure. In some cases a different kind (plate form) of germination tube was observed on hard cuticular structures such as a femur or the dorsum of the thorax of both aphids and parasitoid wasps (Figs 2C, D). Residues of the mucus layer from germ tubes was occasionally seen on the cuticle. Between 96 and $120 \mathrm{~h}$ post treatment, massive sporulation was observed on the cuticles of aphids, parasitoids and mummified aphids (Figs $2 \mathrm{G}$ and $3 \mathrm{~A}, \mathrm{~B}$ and $\mathrm{E}$ ).

\section{DISCUSSION}

The results of the current study revealed that a mucilaginous matrix is secreted by $L$. muscarium at the points of contact with its hosts. Yan et al. (1996) report a positive correlation between the production of an extracellular sheath by L. muscarium and adhesion to the host barrier. It suggested that the mucilage is the matrix in which extracellular enzymes are active in hydrolyzing host cuticle. The protolytic enzymes and chitinase produced by the fungus facilitate penetration of insect integument (Smith et al., 1981). However the secretion of a mucilage-like substance is reported for few entomopathogenic fungi, such as Zoophthora (= Erynia) radicans (Byefeld) Batko (Wraight et al., 1990), Conidiobolus obscurus (Hall \& Dunn) Remaudier \& Keller (Brey et al., 1986), B. bassiana and M. anisopliae (St. Leger, 1993), and its nature, origin and composition (in vivo) are unknown.

Our observations demonstrate the following sequence of events in the infection of hosts by L. muscarium: (I) 


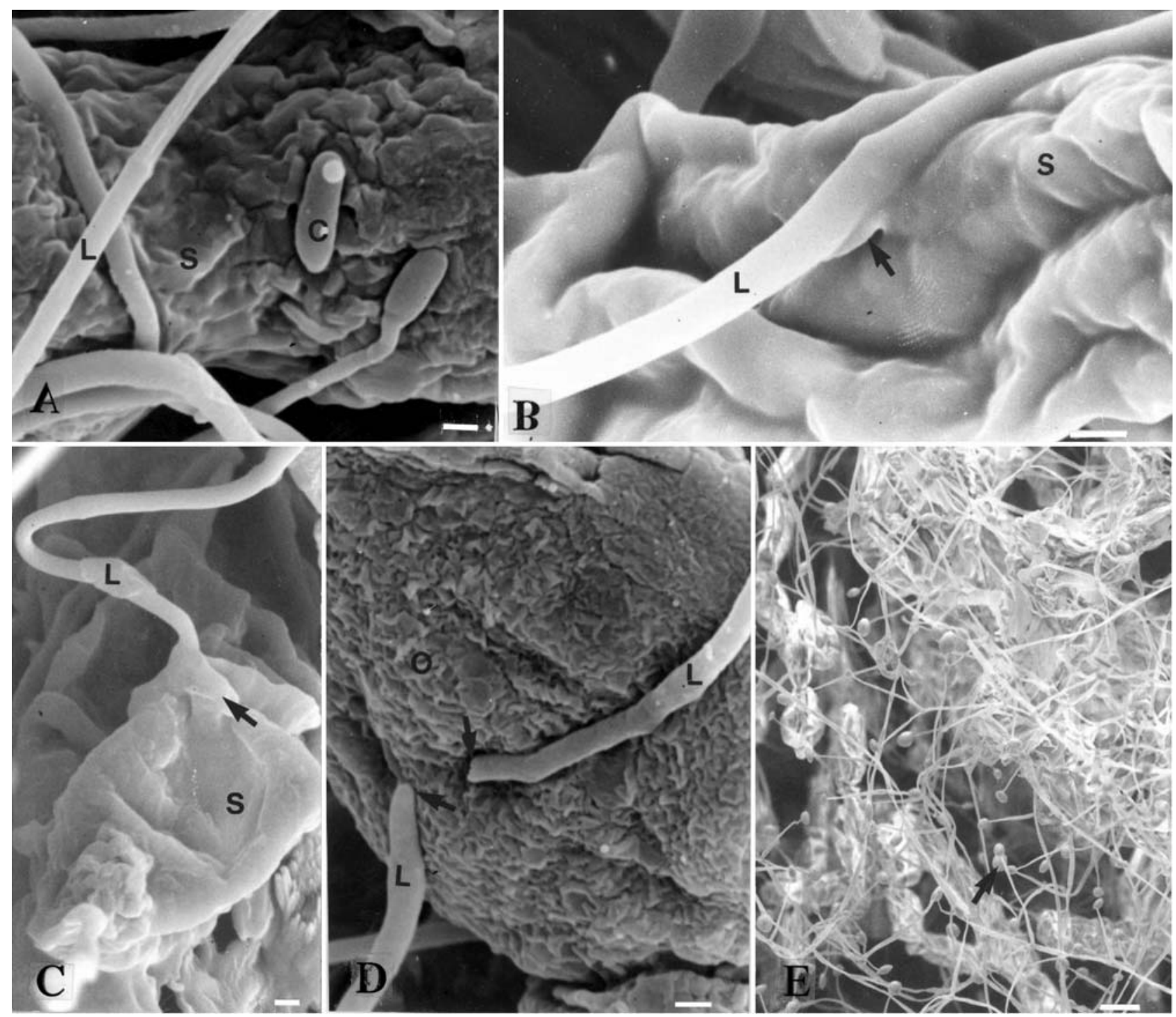

Fig. 1. Scanning electron micrographs of the hyphae (H) of Sphaerotheca fuliginea (S), treated with Lecanicillium muscarium (L). A - Germination of conidium (C) on hyphae of $S$. fuliginea, showing developing germination tube (Gt), $24 \mathrm{~h}$ after treatment, bar $=1$ $\mu \mathrm{m}$. B - Secretion of mucilagenous matrix by L. muscarium in zone of contact (arrow), $48 \mathrm{~h}$ after treatment, bar $=1 \mu \mathrm{m}$. C - Formation of an appressorium (in some cases) at the tip of the germ tube, bar $=1 \mu \mathrm{m}$. D - possible site of penetration (arrows) into the host oidium $(\mathrm{O}), \mathrm{bar}=1 \mu \mathrm{m}$. E - Massive sporulation of L. muscarium on residues of powdery mildew, $96-120 \mathrm{~h}$ after treatment, bar $=$ $10 \mu \mathrm{m}$.

attachment to the host, (II) conidium germination and formation of germ tube, (III) mycelium development on the host, (IV) penetration and growth of the pathogen on/in the host and (V) sporulation on the surface of the host's body. These observations coincide with the commonly described sequence of events characterizing other entomopathogenic fungal infections (Charnley, 1989). They complement detailed microscopical study of Schreiter et al. (1994) and Sitch \& Jackson (1997), who examined the ultrastructural aspects of the interaction between L. muscarium and its hosts. Our results, furthermore, demonstrate that germination and multiplication of $L$. muscarium on powdery mildew, aphids and mummified aphid occurred within 48-72 h after treatment. The germination and development of fungal propagules of Entomophthoralean and Hyphomycetes fungi on the surface of their hosts are regulated by numerous physicochemical and nutritional parameters (Bery et al., 1986; Hajek \& Eastburn, 2003). For example, free amino acids and monosaccharides originating from cuticular extracts favour the formation of germ tubes and development of C. obscurus and $M$. anisopliae conidia (Hajek \& Eastburn, 2003). Rapid conidial germination and mycelial development of L. muscarium on both aphid and cucumber powdery mildew colonies can be explained by the presence of stimulatory components in the chitin barrier of these hosts, as shown by Askary et al., (1997, 1999) using TEM.

L. muscarium develops on the surface of its host and produces branched and septate hyphae that ramify and sporulate. This strategy allows the fungus to exploit a wide range of structural components of the host (Charn- 

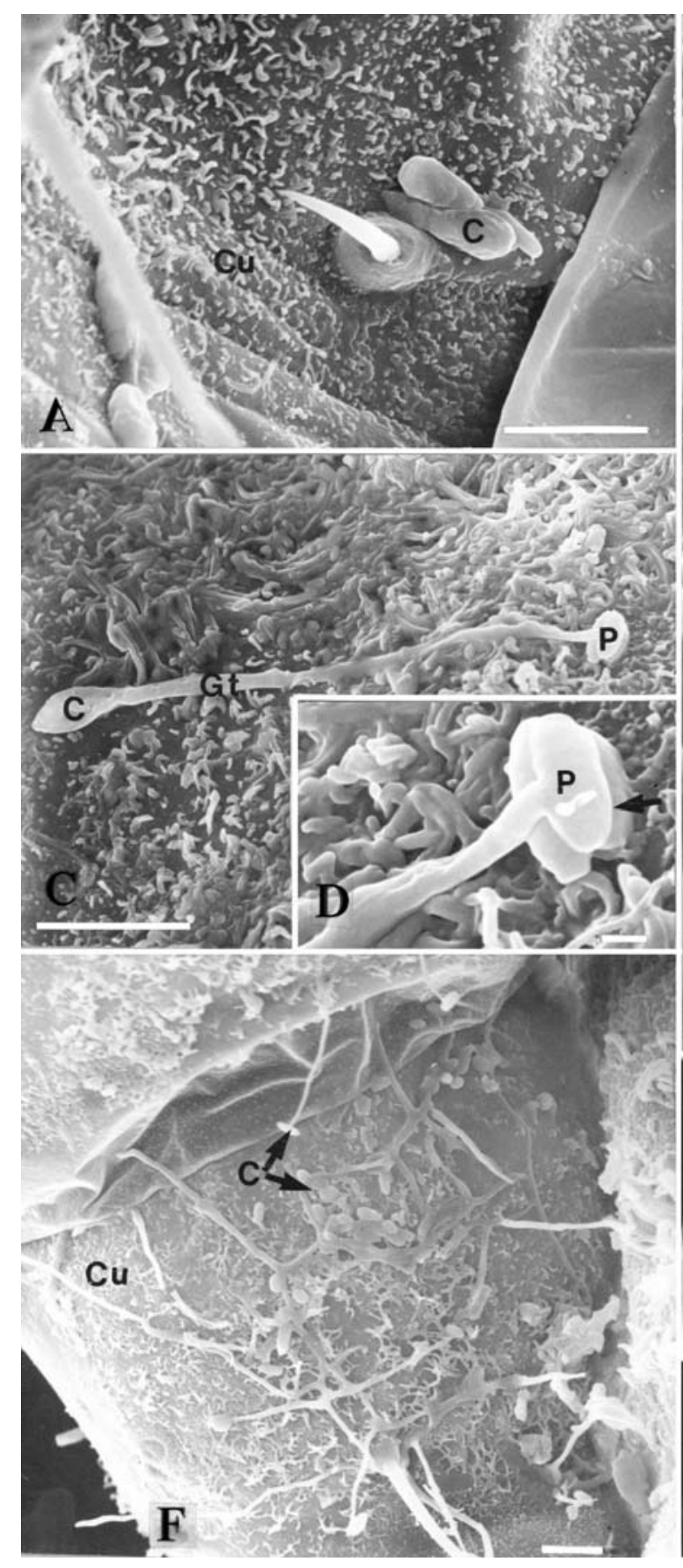

Fig. 2. Scanning electron micrographs of the cuticle $(\mathrm{Cu})$ of Macrosiphum euphorbiae, treated with Lecanicillium muscarium $(\mathrm{L})$. A - Germination of conidium (C), $24 \mathrm{~h}$ after treatment, bar $=10 \mu \mathrm{m}, \mathrm{B}$ - Conidia adhering to aphid cuticle, secretion of mucilaginous matrix (arrow) and developing germination tube (Gt), bar $=1 \mu \mathrm{m} . \mathrm{C}$ and $\mathrm{D}$ - Formation of an appressorium (P) (in some cases) at the tip of a germination tube (Gt), bars $=1 \mu \mathrm{m}(\mathrm{C}), 10 \mu \mathrm{m}$ (D). E - Possible site of penetration (arrow), bar $=1 \mu \mathrm{m}$. F - Development of hyphae on aphid cuticle and sporulation at this time (in some cases), $48 \mathrm{~h}$ after treatment, bar $=10 \mu \mathrm{m}$. $\mathrm{G}-\mathrm{Sporulation}$ on surface of aphid, $120 \mathrm{~h}$ after treatment, bar $=100 \mu \mathrm{m}$.

ley, 1989). For some entomopathogenic fungi, such as $Z$. radicans, this phenomenon results in a high rate of production of germ tubes on the host's abdomen that ramify and penetrate the cuticle (Wraight et al., 1990). The early production of large numbers of conidia on the host surface (as observed on powdery mildew, aphids and mummified aphids), possibly facilitates the spread of the fungus in host populations or phytopathogen colonies, when environmental conditions are favourable (Heale et al., 1988; Brooks, 1993). Furthermore, mycelial development on the host surface also enhances the probability of penetration.

Effects of entomopathogenic fungi on non target hosts such as parasitoids are recorded (Flexner et al., 1986; Brooks, 1993). Pathogenic fungi may deleteriously affect different developmental stages of parasitoids (Brooks, 

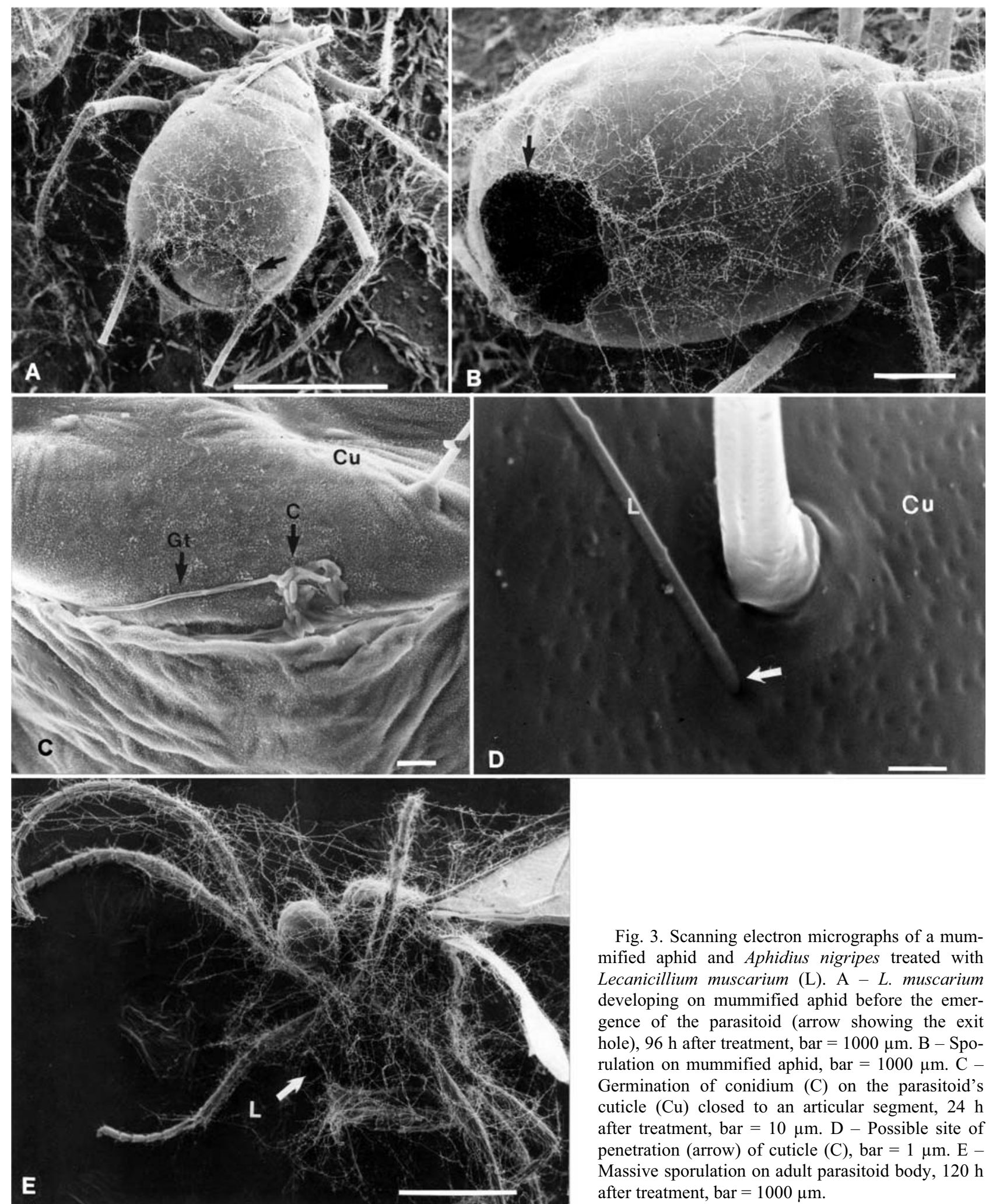

Fig. 3. Scanning electron micrographs of a mummified aphid and Aphidius nigripes treated with Lecanicillium muscarium (L). A - L. muscarium developing on mummified aphid before the emergence of the parasitoid (arrow showing the exit hole), $96 \mathrm{~h}$ after treatment, bar $=1000 \mu \mathrm{m}$. B - Sporulation on mummified aphid, bar $=1000 \mu \mathrm{m}$. C Germination of conidium (C) on the parasitoid's cuticle $(\mathrm{Cu})$ closed to an articular segment, $24 \mathrm{~h}$ after treatment, bar $=10 \mu \mathrm{m}$. D - Possible site of penetration (arrow) of cuticle (C), bar $=1 \mu \mathrm{m}$. E Massive sporulation on adult parasitoid body, $120 \mathrm{~h}$ after treatment, bar $=1000 \mu \mathrm{m}$.

1993). Askary \& Brodeur (1999) studied the susceptibility of larval stages of $A$. nigripes in parasitized aphids, using light microscopy. They showed that a dense aggregation of L. muscarium hyphal bodies may favour localized penetration by the fungus. The present study further clarified some aspects of the indirect infection of $A$. nigripes adults by $L$. muscarium (when parasitoid emerges from the mummy) and direct infection (when fungal spores contaminate adults). However, development and sporulation of L. muscarium was observed on mummified aphids and adult parasitoids, but more information is needed about the susceptibility of adult parasitoids to the fungus. In particular, the mortality attributable to indirect and direct infection at different concentrations of fungal infective units (LC50), time to 50 percent mor- 
tality (LT50) and the effect of the fungus on the behaviour and oviposition of parasitoid adults.

ACKNOWLEDGMENTS. The authors wish to thank J. Brodeur and N. Benhamou, professors at Laval University, for their assistance. This research was supported by the government of the Islamic Republic of Iran and Research Institut of Forests and Rangelands.

\section{REFERENCES}

AlLen D.J. 1982: Verticillium lecanii on the bean rust fungus, Uromyces appendiculatus. Trans. Br. Mycol. Soc. 79: 362-364.

Askary H. \& Brodeur J. 1999: Susceptibility of larval stages of aphid parasitoid, Aphidius nigripes to the entomopathogenic fungus Verticillium lecanii. J. Invert. Pathol. 73: 129-132.

Askary H., Benhamou N. \& Brodeur J. 1997: Ultrastructural and cytochemical investigations of the antagonistic effect of Verticillium lecanii on cucumber powdery mildew. Phytopathology 87: 359-368.

Askary H., Carrière Y., Bélange R.R. \& Brodeur J. 1998: Pathogenicity of the fungus Verticillium lecanii to aphids and powdery mildew. Biocontr. Sci. Technol. 8: 23-32.

Askary H., Benhamou N. \& Brodeur J. 1999: Characterization of aphid invasion by the hyphomycete Verticillium lecanii. $J$. Invert. Pathol. 74: 1-13.

Benhamou N. \& Brodeur J. 2000: Evidence for antibiosis and induced hosts defense reactions in the interaction between Verticillium lecanii and Penicillium digitatum, the causal agent of green mold. Phytopathology 90: 932-943.

Benhamou N. \& Brodeur J. 2001: Pre-inoculation of Ri T-DNA transformed cucumber roots with the mycoparasite, Verticillium lecanii, induces host defense reactions against Pythium ultimum infection. Physiol. Molec. Plant Pathol. 58: 133-146.

Brey P.T., Latge J.P. \& Prevost M.C. 1986: Integumental penetration of the pea aphid, Acyrthosiphon pisum, by Conidiobolus obscurus (Entomophthoraceae). J. Invert. Pathol. 48: 34-41.

Brodeur J. \& McNeIL J.N. 1994: Seasonal ecology of Aphidius nigripes (Hymenoptera: Aphidiidae), a parasitoid of Macrosiphum euphorbiae (Homoptera: Aphididae). Environ. Entomol. 23: 292-298.

BrooKs W.M. 1993: Host-parasitoid-pathogen interactions. In Beckage N.E., Thompson S.N. \& Federici B.A. (eds): Parasites and Pathogens of Insects: Pathogens. Academic Press, San Diego, pp. 231-272.

Burge M.N. 1988: The scope of fungi in biological control. In Burge M.N. (ed.): Fungi in Biological Control System. Manchester University Press, UK, pp. 1-18.

CHARNLEY A.K. 1989: Mechanisms of fungal pathogenesis in insects. In Whipps J.M. \& Lumsden R.D. (eds): The Biotechnology of Fungi for Improving Plant Growth. Cambridge University, London, pp. 85-125

Charnley A.K. \& St. Leger R.J. 1991: The role of cuticledegrading enzymes in fungal pathogenesis in insects. In Cole G.T. \& Hoch H.C. (eds): The Fungal Spore and Disease Initiation in Plants and Animals. Plenum Press, New York, pp. 267-286.
Clarkson J.M. \& Charnley A.K. 1996: New insights into the mechanisms of fungal pathogenesis in insects. Trends Microbiol. 4:197-203.

Flexner J.L., Lighthart B. \& Croft B.A. 1986: The effects of microbial pesticides on non-target, beneficial arthropods. Agric. Ecosyst. Environ. 16: 203-254.

HajeK A.E. \& EAstburn C.C. 2003: Attachment and germination of Entomophaga maimaiga conidia on host and non-host larval cuticle. J. Invert. Pathol. 82: 12-22.

HALL R.A. 1980: Laboratory infection of insects by Verticillium lecanii strains isolated from phytopathogenic fungi. Trans. Br. Mycol. Soc. 74: 445-446.

HaLl R.A. 1981: The fungus Verticillium lecanii as a microbial insecticide against aphids and scales. In Burges H.D. (ed.): Microbial Control of Pests and Plant Diseases. Academic Press, London, pp. 483-498.

Heale J.B., Isaac J.E. \& Chandler D. 1988: Prospects for strain improvement in entomopathogenic fungi. Pestic. Sci. 26: 79-92.

Meyer S.L.F., Huettel R.N. \& Sayre R.M. 1990: Isolation of fungi from Heterodera glycines and in vitro bioassays for their antagonism to eggs. J. Nematol. 22: 532-537.

Moino Jr. A., Alves S.B., Lopes R.B., Neves P.M.O.J., Pereira R.M. \& VIEIRA S.A. 2002: External development of the entomopathogenic fungi Beauveria bassiana and Metarhizium anisopliae in the subterranean termite Heterotermes tenuis. Scientia Agric. 59: 267-273.

RaghaVEndRa-Rao N.N. \& PAVGi M.S. 1977: Two mycoparasites on powdery mildews. Sydowia 30: 145-147.

Schreiter G., Butt T.M., Beckett A., Vestergaard S. \& Moritz G. 1994: Invasion and development of Verticillium lecanii in the western flower thrips, Frankliniella occidentalis. Mycol. Res. 98: 1025-1034.

Sitch J.C. \& JACKSON C.W. 1997: Pre-penetration events affecting host specificity of Verticillium lecanii. Mycol. Res. 101: $535-541$.

Smith R.J., Pekrul S. \& Grula E.A. 1981: Requirement for sequential enzymatic activities for peneteration of the integument of the corn earworm (Heliothis zea). J. Invert. Pathol. 38: $335-344$.

Spencer D.M. \& AtKey P.T. 1981: Parasitic effects of Verticillium lecanii on two rust fungi. Trans. Br. Mycol. Soc. 77: $535-542$.

St. Leger R.S. 1993: Biology and mechanisms of insect-cuticle invasion by Deuteromycete fungal pathogens. In Beckage N.E., Thompson S.N. \& Federici B.A. (eds): Parasites and Pathogens of Insects. Vol. 2: Pathogens. Academic Press, San Diego, pp. 211-229.

Wraight S.P., Butt T.M., Galaini-Wraight S., Allee L.L., SOPER R.S. \& RoBerTs D.W. 1990: Germination and infection processes of the entomophthoralean fungus Erynia radicans on the potato leafhopper, Empoasca fabae. J. Invert. Pathol. 56: $157-174$.

Yan J., Li L.Z., Evans H.C. \& Godvin G.R. 1996: Observations on the micromorphology of Verticillium using cryo-scanning electron microscopy. Acta Mycol. Sin. 15: 34-37.

ZARE R. \& GAMS W. 2001: A revision of Verticillium section Prostrata. IV. The genera Lecanicillium and Simplicillium gen. nov. Nova Hedvigia 73: 1-50.

Received April 20, 2006; revised and accepted September 6, 2006 